\title{
CYP17 gene polymorphism and its association with high-risk north Indian breast cancer patients
}

\author{
Anurupa Chakraborty $\cdot$ N. S. Murthy • \\ Chintamani Chintamani · D. Bhatnagar · \\ R. S. Mohil · P. C. Sharma $\cdot$ Sunita Saxena
}

Received: 25 June 2006/ Accepted: 16 November 2006/Published online: 18 January 2007

(C) The Japan Society of Human Genetics and Springer 2007

\begin{abstract}
A single $\mathrm{T}>\mathrm{C}$ change at the $5^{\prime}$ promoter region of the CYP17 gene is reported to be associated with increased risk of breast cancer. This study evaluates the influence of genetic polymorphism of CYP17 on breast cancer susceptibility. Two hundred and fortytwo patients with histopathologically confirmed breast cancer and 212 age-matched controls were included in the present study. Information relating to age at onset of the disease, family history and estrogen receptor status was elicited. Investigation for CYP17 polymorphism was carried out in 106 early onset, 80 late onset and 56 familial cases. The frequencies of two CYP17 alleles were also analyzed in $116(47.9 \%)$ cases with known estrogen receptor (ER) status confirmed immunohistochemically. A polymerase chain reaction-restriction fragment length polymorphism (PCR-RFLP) method was used to detect the polymorphism, and the genotypes identified were assigned as homozygous wild type (A1A1), heterozygous variant (A1A2), and homozygous variant (A2A2). Associations between the various genotypes in patients and controls were investigated with Fisher's exact test. All the tests were
\end{abstract}

\author{
A. Chakraborty $\cdot$ S. Saxena $(\square)$ \\ Institute of Pathology, Safdarjang Hospital Campus, \\ New Delhi, India \\ e-mail: sunita_saxena@yahoo.com \\ N. S. Murthy \\ NCRP (ICMR), Bangalore, India \\ C. Chintamani - D. Bhatnagar - R. S. Mohil \\ Safdarjang Hospital, New Delhi, India \\ P. C. Sharma \\ Guru Govind Singh Indraprastha University, \\ Kashmiri Gate, Delhi, India
}

two tailed. The results showed that the frequency of heterozygous and homozygous CYP17 genotype was higher in early onset breast cancer patients (94.3\%) than in controls $(80.3 \%)$, and the difference was significant $(P=0.001)$. A highly statistically significant increased risk in carriers of homozygous A2 allele was found in young patients $(P \leq 0.001)$ in comparison with patients having late onset condition $(P=0.260)$. However, no significant association between the genotype and breast cancer risk was observed among women with strong family history. Further, data had showed that patients $(80.6 \%)$ with at least one A2 allele tended to exhibit ER-independent cell proliferation, although statistical significance could not be established $(P=0.160)$. The present findings suggest that CYP17 A2 allele gene polymorphism might play a significant role in breast cancer development in young Indian women.

Keywords CYP17 gene - Polymorphism in north Indian population - Early onset breast cancer . Familial breast cancer - Correlation with ER status

\section{Introduction}

The breast is the second most common site of cancer in Indian women after cervix uteri. The average age of Indian breast cancer patients has been reported to be 50-53 years (National Cancer Registry Programme [NCRP] 2001) in various population-based registries located in the different parts of the country, whereas, in US white women, the average age of occurrence has been reported to be 61 years (Parkin et al. 2002). This reveals that the disease occurs a decade earlier in the 
Indian population than in western countries. Thus, the reasons for the early age of occurrence amongst Indian women need to be studied.

The etiology of breast cancer in younger and older women differs in terms of inheritance, carcinogenesis and prognosis (Nixon et al. 1994; Bonnier et al. 1995). Hormonal risk is one of the non-genetic factors that may contribute to the disease's etiology. Several clinical, epidemiological and experimental studies have proved that estrogen and progesterone play a major role in the growth of normal breast tissue (Lupulescu 1995; Berstein and Press 1998), and breast cancer risk is strongly related to exposure to these endogenous steroid hormone levels (Pike et al. 2004), specifically estrogen (Feigelson and Henderson 1996). Although the exact mechanisms remain to be fully elucidated, the alkylation of cellular molecules and the generation of active radicals that can damage DNA (Nandi et al. 1995), together with the potential genotoxicity of estrogen and some of its metabolites (e.g. the catechol estrogens) (Nandi et al. 1995; Yager and Liehr 1996), have been implicated.

According to some studies, genetic polymorphism in genes related to the biosynthesis and metabolism of hormones and polycyclic aromatic hydrocarbons is associated with an altered risk of breast cancer and other types of cancer (Zhong et al. 1993; Abrosone et al. 1995; Taioli et al. 1995; Feigelson et al. 1997; Lavigne et al. 1997; Thompson et al. 1998). It is assumed that, among ethnic groups, genetic differences exist that effect steroid hormone metabolism and transport. Because cumulative exposure to circulating estrogen has been linked to increased risk of breast cancer, interest has been focused on the enzymes regulating the biosynthetic and metabolic pathways of these hormones.

The estrogen-forming ovary expresses the CYP17 gene (Hanukoglu 1992), which codes for the cytochrome P450c17a enzyme and is located on chromosome 10, spans 6,569 bp, and is divided into eight exons (Picado-Leonard and Miller et al. 1987). The cytochrome P450c17a enzyme mediates both steroid 17a-hydroxylase and 17,20 lyase activities and functions at key branch points in human steroid genesis (Brentano et al. 1990). In steroidogenesis, cholesterol is first converted to pregnenolone, by an enzyme encoded by CYP11a, and then to progesterone by $3 \beta$-hydroxysteroid dehydrogenase; 17a-hydroxylase converts pregnenolone and 17-hydroxyprogesterone, respectively. A single polymorphism, $\mathrm{T}->\mathrm{C}$, in the CYP17 gene, which codes for the above enzyme involved in estrogen synthesis, creates an additional $\mathrm{Sp}$ I- type promoter site (CCACC) 34 bp upstream of the initiation of translation but downstream of the transcription start site (Carey et al. 1994), which is associated with increased estrogen levels. The base pair change also creates a recognition site for the MspA1 digestion of a polymerase chain reaction (PCR) product that has been used to designate arbitrarily two alleles, A1 and A2. It has been reported that women who are heterozygous or homozygous for the CYP 17 A2 allele show comparatively higher serum levels of estradiol than do women with an A1/A1 genotype (Feigelson et al. 1998).

To investigate the role of CYP17 gene polymorphism in high-risk Indian breast cancer patients, and mainly targeting early onset breast cancer and familial cases, we studied a total of 242 cases for CYP 17 gene polymorphism. We analyzed frequencies of the two CYP 17 alleles in (a) a group of young breast cancer patients ( $\leq 40$ years) and late-onset cancer patients and (b) familial breast cancer patients. We additionally investigated whether expression of steroid receptor has any association with CYP17 polymorphism.

\section{Materials and method}

\section{Study population}

Two hundred and forty-two patients with histologically confirmed breast cancer, referred from the departments of Surgery and Cancer Surgery of Safdarjang Hospital, New Delhi, and LLRM Medical College, Meerut, during 1999-2003, were selected for the study.

Of the 242 breast cancer patients, 106 were young (below 40 years), 80 (above 40 years) had a late-onset condition, and 56 had a family history of cancer of the breast, or ovary, or both. The patient's ages ranged from 13 years to 78 years, with a mean age of 41.9 years $(\mathrm{SD} \pm 11.8$ years $)$.

Informed consent was obtained from all the participating patients, and the study was carried out with the approval of the Ethics Review Committee of Safdarjang Hospital, New Delhi.

A series of 212 age-matched ( \pm 2 years) controls, matched for early (106) and late (80) age breast cancer, was selected from the women attending antenatal checkups and from blood bank donors in Delhi. For some of the cases more than one control was selected. The mean age of controls was 39.9 years $(\mathrm{SD} \pm 11.5$ years). While selecting controls we took care to see that no differences existed with regard to the ethnicity of the breast cancer patients. No separate controls with a family history were selected for the patients with a family history of breast cancer, and the comparison was 
carried out with the same group of control subjects selected earlier according to early and late onset. The mean ages between breast cancer patients with a family history and the control series were almost similar. Here, it can be said, it was more similar to frequency matching.

Estrogen receptor (ER) status was estimated immuno-histochemically in 116 cases; 93 (80.1\%) ER negative and $23(19.8 \%)$ ER positive cases were included in the present study to find out the association between estrogen receptor status and CYP17 genotype.

Blood sample collection

Peripheral blood samples $(\mathrm{ca} .10 \mathrm{ml})$ from all patients and controls were collected into EDTA vials. The buffy coat was separated and frozen at $-70^{\circ} \mathrm{C}$ for further use.

\section{DNA extraction}

Genomic DNA was extracted from peripheral blood lymphocytes by the standard phenol-chloroform extraction method. Blood was first digested with lyses buffer I (30 mM Tris, $5 \mathrm{mM}$ EDTA and $50 \mathrm{mM} \mathrm{NaCl})$ and lyses buffer II (20\% SDS, $100 \mu \mathrm{g} / \mathrm{ml}$ Prot.K), followed by extraction with Tris-saturated phenol and chloroform-isoamyl alcohol (24:1), and finally recovered by ethanol precipitation.

\section{PCR reaction}

Briefly, a PCR fragment containing the base pair change was generated using the following primers: CYP17 F-5'CATTCGCACTCTGGAGTC $3^{\prime}$ and CYP17 R-5'AGGCTCTTGGGGTACTTG 3'.

The PCR reactions were carried out in $25 \mu$ laliquots containing approximately $50 \mathrm{ng}$ genomic DNA, 20 pmole of each primer, $1 \times$ reaction buffer, $100 \mu \mathrm{M}$ deoxynucleotide triphosphates, and one unit of Taq polymerase. The reaction was performed in an Eppendorf thermal cycler, and the DNA was denatured at $94^{\circ} \mathrm{C}$ for $5 \mathrm{~min}$ and amplified during 30 cycles of $94^{\circ} \mathrm{C}$ for $1 \mathrm{~min}$, annealing at $57^{\circ} \mathrm{C}$ for $1 \mathrm{~min}$, extension at $72^{\circ} \mathrm{C}$ for $1 \mathrm{~min}$, with final extension at $72^{\circ} \mathrm{C}$ for $5 \mathrm{~min}$.

\section{Restriction fragment length polymorphism analysis}

The PCR products were digested with MspA1 at $37^{\circ} \mathrm{C}$ for $3 \mathrm{~h}$. The reaction mixture was as follows: $15 \mu \mathrm{l}$ of PCR product, $2.5 \mu \mathrm{l}$ of digestion buffer, $0.25 \mu \mathrm{l}$ of BSA and $0.5 \mu \mathrm{l}$ of restriction enzyme MspA1. The digested fragments were visualized on $2 \%$ agarose gel with ethidium bromide staining to identify the base pair change.

\section{Statistical analysis}

Fisher's exact test was applied to find out the association between breast cancer and CYP 17 genotype for all cases combined together and by onset condition and family history.

Furthermore, the allelic frequencies in the control population were calculated by the $\chi^{2}$ test to find out the consistency with the Hardy-Weinberg equilibrium.

\section{Results}

We examined the $\mathrm{T}>\mathrm{C}$ polymorphism of the CYP17 gene in both sporadic and familial breast cancer and in a suitable control population. Analysis was conducted for 242 cases, including 106 cases of early onset, 80 of late onset, and 56 familial cases, together with 212 agematched controls.

Patterns of homozygosity and heterozygosity of the A2 allele and homozygosity of the A1 allele are illustrated in Figs. 1 and 2. Significance was calculated to evaluate the risk of breast cancer for $\mathrm{A} 2$ allele carriers (A2/A2, A1A2 and A1A2 + A2A2). Considering the early onset cases, when the allele frequencies of the CYP17 polymorphism were compared between the affected and control population, we observed a significant difference $(P=0.001)$ (Table 1). Young women heterozygous and homozygous for the $\mathrm{A} 2$ allele were four times more likely to have breast cancer. When breast carcinoma cases with $\mathrm{A} 2 \mathrm{~A} 2$ was considered alone, the $P$ value was found to be highly statistically significant $(P \leq 0.001)$. The data showed that $40.5 \%$ of the affected population had the A2A2 genotype compared with $25.1 \%$ of the control population. Only

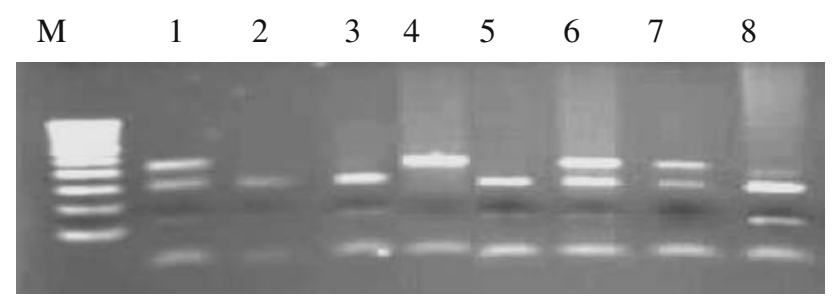

Fig. 1 MspA1 restriction fragments of CYP17 alleles separated by agarose gel electrophoresis. Lane $M$ contains a m.w. marker (100-bp ladder) and the homozygous A1 genotype is shown in lane 4; the heterozygous pattern in lanes 1, 6 and 7 and the homozygous A2 genotype in lanes 2, 3, 5 and 8 


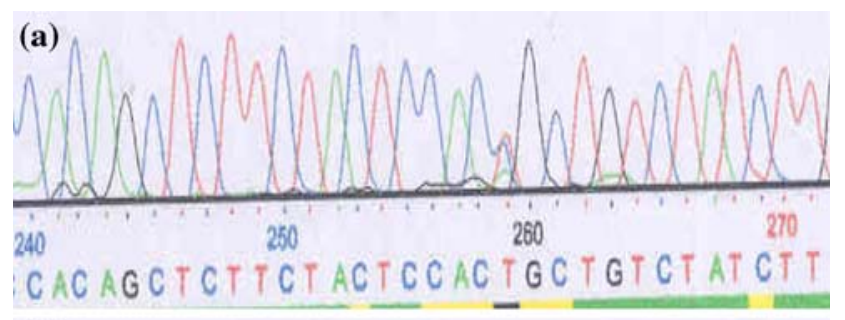

(b)

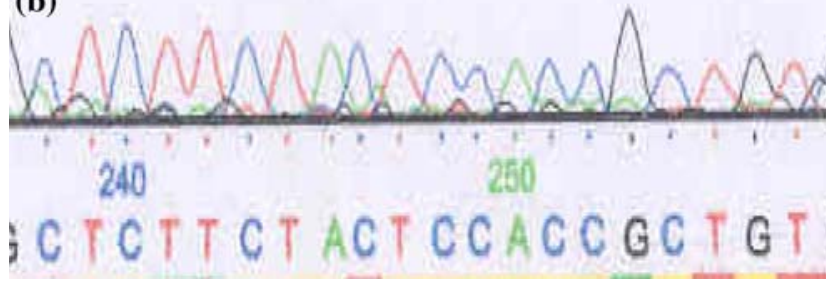

Fig. 2 Electrofluorogram representing (a) heterozygous and (b) homozygous condition of the CYP17 A2 allele

$5.6 \%$ of the affected population had the A1 allele, compared with $19.6 \%$ of the controls.

The distribution of $\mathrm{A} 2$ and $\mathrm{A} 1$ alleles and the association with late-onset condition of cancer are shown in (Table 1). Individuals heterozygous for the A2 allele had a $P$ value of 0.382 , whereas women homozygous for the A2 allele expressed a slightly higher risk $(P=0.260)$, although statistical significance could not be established.

The statistical significance of breast cancer associated with strong family history stratified by genotype and early or late onset is shown in Table 2. The average age of breast cancer patients with a family history
(33.2 years) and of control subjects (32.1 years) in the early onset group were found to be almost similar. Similarly, even in the late onset group, the mean ages of breast cancer patients (53.9 years, with family history) and controls (51.7 years) were also similar. No obvious association was observed between both early onset familial cases $(P=0.768)$ and late onset familial cases $(P=0.675)$ with breast cancer risk when compared with age-matched controls.

Because of the role of CYP17 in estrogen biosynthesis, we next determined whether the genotype was associated with estrogen receptor status. However, the genotype comparison was not carried out according to early and late onset as it resulted in very few subjects in some of the groups.

The association of the CYP17 genotype with steroid receptor expression in breast cancer tissues is shown in Table 3. Cases were analyzed for a possible connection between estrogen receptor status and an additional promoter site for the CYP17 gene in the malignant cells, but no apparent association was observed between ER status and A2 allele polymorphism, although the study has shown that women with negative ER expression were at twice the risk of breast cancer when associated with the $\mathrm{C}$ allele $(P=0.160)$.

\section{Discussion}

The response of an organ to the proliferative effects of a hormone may be a progression from normal growth

Table 1 Distribution of CYP17 genotype frequencies in early and late onset breast cancer patients with no family history and in agematched controls, together with $P$ values (Values in parentheses indicate percentages, $n$ number of subjects studied)

\begin{tabular}{|c|c|c|c|c|c|c|}
\hline \multirow[t]{2}{*}{ Genotype } & \multicolumn{3}{|l|}{ Early onset } & \multicolumn{3}{|l|}{ Late onset } \\
\hline & $\begin{array}{l}\text { Breast cancer } \\
(n=106)\end{array}$ & $\begin{array}{l}\text { Controls } \\
(n=127)\end{array}$ & $P$ & $\begin{array}{l}\text { Breast cancer } \\
(n=80)\end{array}$ & $\begin{array}{l}\text { Controls } \\
(n=85)\end{array}$ & $P$ \\
\hline A1A2 & $57(53.7)$ & $70(55.1)$ & 0.013 & $41(51.2)$ & $40(47.0)$ & 0.382 \\
\hline $\mathrm{A} 2 \mathrm{~A} 2$ & $43(40.5)$ & $32(25.1)$ & $<0.001$ & $16(20.0)$ & $13(15.2)$ & 0.260 \\
\hline $\mathrm{A} 1 \mathrm{~A} 2+\mathrm{A} 2 \mathrm{~A} 2$ & $100(94.3)$ & $102(80.3)$ & 0.001 & $57(71.2)$ & $53(62.3)$ & 0.250 \\
\hline A1A1 & $6(5.6)$ & 25 (19.6) & - & $23(28.5)$ & 32 (37.6) & - \\
\hline
\end{tabular}

Table 2 Distribution of CYP17 genotype frequencies in familial breast cancer patients and non-familial age-matched controls $(\leq 40 /$ $>40$ years) together with $P$ values (Values in parentheses indicate percentages, $n$ number of subjects studied)

\begin{tabular}{|c|c|c|c|c|c|c|}
\hline \multirow[t]{2}{*}{ Genotype } & \multicolumn{3}{|c|}{ Early onset familial cases } & \multicolumn{3}{|c|}{ Late onset familial cases } \\
\hline & $\begin{array}{l}\text { Breast cancer } \\
(n=22)\end{array}$ & $\begin{array}{l}\text { Controls with no } \\
\text { family history } \\
(n=127)\end{array}$ & $P$ & $\begin{array}{l}\text { Breast cancer } \\
(n=34)\end{array}$ & $\begin{array}{l}\text { Controls with no } \\
\text { family history } \\
(n=85)\end{array}$ & $P$ \\
\hline $\mathrm{A} 1 \mathrm{~A} 2$ & $12(54.5)$ & $70(55.1)$ & 0.756 & $18(55.3)$ & $40(52.6)$ & 0.657 \\
\hline $\mathrm{A} 2 \mathrm{~A} 2$ & $7(31.8)$ & $32(25.1)$ & 0.502 & $5(35.7)$ & $13(31.7)$ & 1.000 \\
\hline $\mathrm{A} 1 \mathrm{~A} 2+\mathrm{A} 2 \mathrm{~A} 2$ & $19(86.3)$ & $102(80.3)$ & 0.768 & $23(91.0)$ & $53(84.4)$ & 0.675 \\
\hline A1A1 & $3(13.6)$ & $25(19.6)$ & - & $11(8.9)$ & $32(15.5)$ & - \\
\hline
\end{tabular}


Table 3 Association between CYP17 genotype in breast cancer cases, together with tumor characteristics and $P$ values (Values in parentheses indicate percentages, $n$ number of subjects studied)

\begin{tabular}{llll}
\hline Estrogen status & & & \\
\hline Genotype & Negative $(n=93)$ & Positive $(n=23)$ & $P$ \\
\hline A1A2 & $46(49.4)$ & $10(43.4)$ & 0.252 \\
A2A2 & $29(31.1)$ & $5(21.7)$ & 0.206 \\
A1A2 + A2A2 & $75(80.6)$ & $15(65.2)$ & 0.160 \\
A1A1 & $18(19.3)$ & $8(34.7)$ & - \\
\hline
\end{tabular}

to hyperplasia to neoplasia. The hypothesis that cumulative exposure of breast tissue to ovarian hormones is one of the major determinants of breast cancer has existed for at least 30 years. According to the polygenic model developed by Henderson and Feilgeson, there are functionally important polymorphisms in the genes encoding enzymes involved in hormone biosynthesis, which lead to differences in individual susceptibility to breast cancer.

Cytochrome CYP17 encoding P-450 17a-hydroxylase is involved in estrogen biosynthesis, and polymorphism of this gene has been identified in the general population. Carey et al. (1994) have described the common polymorphism of the CYP17 gene and have hypothesized that the number of recognition sites for the Sp I transcription factor may influence promoter activity and thereby up-regulate transcription of the CYP17 gene. These could, theoretically, lead to increased levels of the enzyme, which, in turn, might affect the synthesis of estrogen; the major function of estrogen is to stimulate cell growth and proliferation by expressing growth factors via the function of the ER as a transcription activator. Women who are heterozygous or homozygous for a cytochrome CYP17 polymorphism had also shown high serum estradiol concentrations (Haiman et al. 1999; Chako et al. 2004), although the use of an extra binding site has not been confirmed experimentally (Nedelcheva Kristensen et al. 1999).

Our result suggests that the $\mathrm{T}>\mathrm{C}$ polymorphism in the CYP17 gene is associated with an early onset breast cancer risk. In a population of $43.8 \%$ individuals affected by breast cancer and compared with a control population of $60 \%$ individuals with no cancer history, the presence of the A2 allele was significantly associated with an increased risk for breast cancer development. A similar kind of association was evaluated in a case-control study on a Korean population, between the $\mathrm{T}>\mathrm{C}$ polymorphism in the 5'UTR of the CYP17 gene and breast cancer risk (Myung et al. 2005). It was found that homozygosity for the 5'-UTR variant
(CYP17) is most common in East Asian (32\%) and Japanese $(22 \%)$ populations and is less common among White [mainly European and North American $(14 \%)$ ] and Black [mainly African-American (13\%)] populations, but selection biases are likely to have affected these frequency estimates (Sharp et al. 2004).

Levels of circulating estrogens and androgens may be important in the etiology of premenopausal breast cancer (Eliassen et al. 2006). Analysis of the CYP17 genotype in relation to onset condition has revealed that the A2 allele mediates an increased risk of breast cancer in premenopausal women compared with postmenopausal women. A similar viewpoint has been put forward by a study conducted by the South-East Sweden Health Care Region, where it showed a statistically significant association between CYP17 genotype and early onset breast cancer (Malin et al. 1999). The data from a case-control study conducted on Australian women suggested that women with the CYP17 CC genotype are at an increased risk of early onset breast cancer (Spurdle et al. 2000). Several investigators have demonstrated that breast cancer in young women, compared with older counterparts, is different in terms of pathological features and prognosis, thus suggesting that early onset and late onset breast cancer may have different biological origins. Thus, it could be said that CYP17 gene polymorphism may play a different role in early onset breast cancer cases because the breast etiology may vary between premenopausal and postmenopausal women (Thompson et al. 1998). The criteria used for the selection of the control population may also have influenced the result. However, the genotype dispersal in our control subjects was within that expected and did not deviate from the HardyWeinberg equilibrium.

We have not found any significant effect of CYP17 polymorphism on familial breast carcinoma. It may be possible that the other genes involved in hormone biosynthesis pathway may be playing an important role at the genetic level in familial cases. This has raised a need for studies on the potential role of other genes encoding for estrogen metabolism and transport enzymes in individual breast cancer susceptibility (Coughlin and Piper 1999).

Analysis of tumor characteristics in relation to genotype revealed that breast tissue lacking estrogen receptor was most common among carriers of the A2 allele. Although overall statistical significance could not be established, the CYP17 polymorphism has been found significantly more often in breast cancer cases without estrogen receptor $(80.6 \%)$ than in estrogen receptor positive cases $(65.2 \%)$. Initiation of malignancy and subsequent clonal expansion may occur 
among proliferating cells that lack hormone receptors but are stimulated by the increased level of estrogen caused by the A2 allele. The reason could be that, recently, it has been demonstrated that estrogen can also stimulate cell proliferation without expressing any molecules. The pathway, known as a nongenomic pathway, does not involve ER but requires a G-protein-coupled receptor called GPR30. Experiments suggest that estrogen may bind to GPR30, activating metalloproteinases to cleave heparin-bound epidermal growth factor (EGF). The released EGF can then stimulate cell proliferation by acting on its EGF receptor (Clevenger 2004; Gilbey et al. 2004).

In conclusion, our present study suggests that there exists a possible correlation between CYP17 genotype and breast cancer and that the polymorphism in the same gene influences early onset breast cancer by increasing the risk of the disease in individuals carrying the A2 allele. This provides an important early step in defining a model that can explain individual susceptibility in terms of genetic susceptibility and endogenous estrogen exposure. The A2 allele of the CYP17 gene is responsible for increased estrogen levels, and, more recently, the steroid hydroxylases themselves have been found to be promising new targets for drug development. Instead of the use of anti-hormones to inhibit the action of steroid hormones at the level of steroid hormone receptors CYPs may be used to help in the development of new inhibitors of hydroxylase enzymes (Hakki and Bernhardth 2006).

As a genetic marker, the CYP17 genotype may provide a tool for identifying high-risk groups of women, especially considering the early onset condition, for disease prevention and early treatment.

Acknowledgments We thank the patients and their families, without whose cooperation this study would not have been possible. Financial assistance from ICMR is gratefully acknowledged.

\section{References}

Abrosone BC, Freudenheim JL, Graham S, Marshall JR, Vena JE, Brasure JR, Laughlin R, Nemoto T, Shields PG (1995) Cytochrome P4501A1 and glutathione S-transferase (MI) genetic polymorphism and postmenopausal breast cancer risk. Cancer Res 55:3483-3485

Berstein L, Press MF (1998) Does estrogen receptor expression in normal breast tissue predict breast cancer risk? J Natl Cancer Inst 90:5-9

Bonnier P, Romain S, Charpin C, Lejeune C, Tubiana N, Marte PM, Piana L (1995) Age as a prognostic factor in breast cancer: relationship to pathology and biological features. Int J Cancer 62:138-144
Brentano ST, Picado-Leonard J, Mellon SH, Miller WL, et al (1990) Tissue specific cyclic adenosine 3'5'-monophosphateinduced and phorbol ester repressed transcription from the human P450c17a promoter mouse cell. Mol Endocrinol 4:1972-1979

Carey AH, Waterworth D, Patel K, White D, Little J, Novelli P, Franks S, Williamson R (1994) Polycystic ovaries and premature male pattern baldness are associated with one allele of steroid metabolism gene CYP 17. Human Mol Genet 3:1873-1876

Chako P, Ranjan B, Mathew BS, Joseph T, Pillai MR (2004) CYP17 and SULTIA1 gene polymorphisms in Indian breast cancer. Breast Cancer 11:380-388

Clevenger CV (2004) Roles and regulation of stat family transcription factors in human breast cancer. Am J Pathol 165:1449-1460

Coughlin SS, Piper M (1999) Genetic polymorphisms and risk of breast cancer. Cancer Epidemiol Biomark Prev 8:1023-1320

Eliassen AH, Missmer SA, Tworoger SS, Spiegelman D, Barbieri RL, Dowsett M, Hankinson SE (2006) Endogenous steroid hormone concentrations and risk of breast cancer among premenopausal women. J Natl Cancer Inst 98:1406-1415

Feigelson HS, Henderson BE (1996) Estrogens and breast cancer. Carcinogenesis (Lond) 17:2279-2284

Feigelson HS, Coetzee GA, Kolonel LN, Ross RK, Henderson BE (1997) A polymorphism in the CYP17 gene increases the risk of breast cancer. Cancer Res 57:1063-1065

Feigelson HS, Shames LS, Pike MC, Coetzee GA (1998) Cytochrome P450c17a gene (CYP17) polymorphism is associated with serum estrogen and progesterone concentrations. Cancer Res 58:585-587

Gilbey AM, Burnett D, Coleman RE, Holen I (2004) The detection of circulating breast cancer cells in blood. J Clin Pathol 57:903-911

Haiman CA, Hankinson SE, Spiegelman D, et al (1999) The relationship between a polymorphism in CYP17 with plasma hormone levels and breast cancer. Cancer Res 59:1015-1020

Hakki T, Bernhardth R (2006) CYP17- and CYP11B-dependent steroid hydroxylases as drug development targets. Pharmacol Ther 111:27-52

Hanukoglu I (1992) Steroidogenic enzymes, structure, function and role in regulation of steroid hormone biosynthesis. J Steroid Biochem Mol Biol 43:779-804

Lavigne JA, Helzlsouer KJ, Huang HY, Strickland PT, Bell DA, Selmin O, Watson MA, et al (1997) An association between the allele coding for a low variant of catecholo-methyltransferase and the risk for breast cancer. Cancer Res 57:54935497

Lupulescu A (1995) Estrogen use and cancer incidence: a review. Cancer Invest 13:287-295

Malin BJ, Massimiliano G, Anna CL, Sten W (1999) Association between CYP17 gene polymorphism and risk of breast cancer in young women. Int J Cancer (Pred Oncol) 84:350 353

Myung HS, Kyoung ML, Jung HY, Seok JN, Jong WK, Keun YY, Sue KP, Dong YN (2005) Genetic polymorphism of CYP17 and breast cancer risk in Korean women. Exp Mol Med 37:11-17

Nandi S, Guzman RC, Yang J (1995) Hormones and mammary carcinogen in mice, rats, and humans: a unifying hypothesis. Proc Natl Acad Sci U S A 92:3650-3657

National Cancer Registry Programme (NCRP) (2001) Consolidated report of the population based cancer registries. Indian Council of Medical Research, New Delhi, pp 19901996 
Nedelcheva Kristensen V, Haraldsen EK, Anderson KB, Lonning PE, Erikstein B, Karesen R, Gabrielsen OS, Borresen-Dale AL (1999) CYP17 and breast cancer risk: the polymorphism in the 5' flanking area of the gene does not influence binding to Sp-1. Cancer Res. 59:2825-2828

Nixon AJ, Neuberg D, Hayes DF, Gelman R, Connolly Jl, Schnitt S, Abner A, Recht A, Vicini F, Harris JR (1994) Relationship of patient age to pathologic features of tumor and prognosis for patients with stage I and II breast cancer. J Clin Oncol 12:888-894

Parkin DM, Whelann SL, Ferlay J, et al. (2002) International Agency for Research on Cancer (IARC). Cancer incidence in five continents vol VIII. IARC, Scientific publication no.155, Lyon, France

Picado-Leonard J, Miller WL, et al (1987) Cloning and sequence of the human gene for P450c17a (steroid 17a-hydroxylase/ 17, 20 lyase): similarity with the gene for P450c21. DNA 6:439-448

Pike MC, Pearce CL, Wu AH (2004) Prevention of cancers of the breast, endometrium and ovary. Oncogene 23:6379-6391

Sharp L, Cardy AH, Cotton SC, Little J (2004) CYP17 gene polymorphisms: prevalence and associations with hormone levels and related factors. A HuGE review. Am J Epidemiol 160:729-740

Spurdle AB, Hopper JL, Dite GS, Chen X, Cui J, McCredie MRE, Giles GG, Southey MC, Venter DJ, Easton DF, Chenevix-Trench G (2000) CYP17 promoter polymorphism and breast cancer in Australian women under age forty years. J Natl Cancer Inst 92:1674-1681

Taioli E, Trachman J, Chen X, Toniolo P, Garte SJ (1995) A CYP1A1 restriction fragment length polymorphism is associated with breast cancer in African-American women. Cancer Res 55:3757-3758

Thompson PA, Shield PG, Freudenheim JL, Stone A, Vena JE (1998) Genetic polymorphism in catechol-O-methyltransferase, menopausal status and breast cancer risk. Cancer Res 58:2107-2110

Yager JD, Liehr JG (1996) Molecular mechanisms of estrogen carcinogenesis. Annu Rev Pharmacol Toxicol 36:203-232

Zhong S, Wyllie AH, Barnes D, Wolf CR, Spur NK (1993) Relationship between the GSTMI genetic polymorphism and susceptibility to bladder, breast and colon cancer. Carcinogenesis 14:1821-1824 